\section{TAKING CARE OF EVERYTHING EDUCATION}

Henry Schein Dental understands the pressures dental professionals are under to keep up to date with their CPD obligations. Now, a new educational initiative from Henry Schein Dental Education, hsdeducation. co.uk, is providing an innovative, practical education resource where dental professionals can access information that will help fulfil all their educational needs. The new website is designed to give the most up-to-date information on a wide variety of CPD courses. Covering everything from new techniques, materials and technology to innovative practice solutions, the site includes details of all Henry Schein Dental's latest courses covering a whole host of disciplines including decontamination, orthodontics, lasers and digital dentistry.

Supported by affiliated partners such as the Academy of Digital
Dentistry, Biohorizons, Dentisan, Kerr, Dentsply Sirona and many more - Henry Schein Dental has developed a high quality programme that ensures educational opportunities are available for the entire practice.

Henry Schein Dental was one of the first organisations to be accredited by the BDIA's new Code of Practice. This Code certifies the quality and independence of the education being offered to dental professionals. So whether it's surgical or implant dentistry, digital or laser technology or you want to ensure your team is up to date with HTM 01-05, Henry Schein Education is there to guide you towards improving your CPD and training.

Register for free today: visit hseducation.co.uk or call 02072981980 for more information.

\title{
SUPPORT THE BRITISH DENTAL GUILD
}

The General Dental Practice Committee (GDPC) officially represents all general dental practitioners (GDPs) in the UK and is recognised by the Government as the committee that negotiates on behalf of those GDPs that contract with the NHS to provide primary dental care services.

It is of paramount importance that these elected, experienced and dedicated colleagues who work tirelessly within the GDPC are financially compensated for this important representative work as they spend time away from their practices to benefit the interests of all GDPs.

The British Dental Guild (BDG) was established in the early years of the NHS to provide a sessional fee which is known as the British Dental Guild Rate (BDGR) and this is paid when the GDPC member is absent from their surgery. The BDGR is also universally recognised by NHS and other organisations as a benchmark rate that is awarded to GDPs when appropriate to do so.

The dental profession is going through a sustained period of unprecedented change and the financial demands placed upon the BDG are steadily increasing. Clearly it is important that the BDG is a viable resource that can be relied upon to provide sustained funding to our knowledgeable representatives.

The BDG has a small financial portfolio that, through skillful management by a Board of Managers, generates around 20\% of its income with the rest coming in the form of donations from Local Dental Committees (LDCs) and the BDG is grateful to them for their support. Inevitably, the BDG is heavily dependent on a steady level of donations from LDCs throughout the year.

Ideally, donations to the BDG should be based upon £25 per LDC dental performer per year but this is only a guide to help LDC Treasurers to assess their donation from within their annual budgets.

Please support the Guild so that it can support those that represent all dentists. The Guild Treasurer can be contacted on: 07770808212 or dentalguild@aol.com and donations sent to 20 Hesketh Road, Southport, Merseyside, PR9 9PD.

\section{CHOOSE A TRAINER YOU'D BE HAPPY TO} TREAT YOU

Facial aesthetics: how do you decide which of the many courses to go on? How do you know the trainers on the day are sufficiently qualified? Some of the courses leave a lot to be desired in the sea of nonregulation, despite the supposed aims of the Keogh report.

Aesthetic Courses UK are headed up by consultant facial plastic and head and neck surgeon Mr Wesam Aleid. He is joined by a number of equally experienced practitioners from the world of dermatology, plastic and maxillofacial surgery. In short, you'll be in the hands of the people you would choose to be treated by.

The lack of regulation is something Mr Aleid and Aesthetic Courses UK find hard to accept. Impassioned arguments on the need for better patient safeguards are the driving force in him accepting the challenge of bringing about the style and standard of course that Aesthetic Courses UK deliver, along with his wider team of trainers.

Who would you rather be taught by: someone who you would choose to treat your nearest and dearest, or someone just to get a certificate?

To contact Aesthetic Courses UK call 02073055585 or visit www.aestheticcourses.uk.

\section{AESTHETIC RESTORATIONS WITHOUT BONDING}

Ionolux is a light-curing glass ionomer restorative material in VITA shades A1, A2, A3, A3.5 and B1, which combines the advantages of glass ionomer materials which those of composites. The dentist can, for example, individually adjust the working time of Ionolux by using a polymerisation light.

Application of Ionolux is quick, and the material can be modelled with ease without sticking to the instrument. It also adapts excellently to cavity walls. Ionolux not only makes conditioning of the ental hard tissue unnecessary, there is also no need to apply a final coat of varnish. Polymerisation times are short and practiceoriented, at 20 seconds per $2 \mathrm{~mm}$ layer. Ionolux is easy to polish, it is biocompatible and releases fluorides.

Our proven Ionolux is now available in the new and particularly practical application capsule, distinguished by the fact that an activator is no longer required. The combined advantages of glass ionomer materials and composites, easy to use with Ionolux: place the filling, polymerise, finish, ready!

Manufacturer: VOCO GmbH, Anton-Flettner-Straße 1-3, 27472 Cuxhaven, Germany, www.voco.com, info@

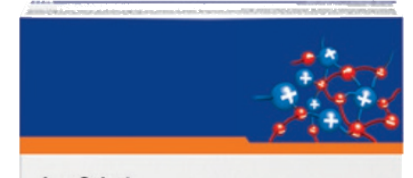
IonoSelect voco.com, telephone 07500769613. 